Bull. Chem. Soc. Ethiop. 2020, 34(1), 163-174.

ISSN 1011-3924

(c) 2020 Chemical Society of Ethiopia and The Authors

Printed in Ethiopia

DOI: https://dx.doi.org/10.4314/bcse.v34i1.16

\title{
GEL TIME PREDICTION OF POLYESTER RESIN FOR LAMINATION OF POLYMER COMPOSITES
}

\author{
C.O. $\mathrm{Ujah}^{1 *}$, A.P.I. Popoola ${ }^{1}$ and I.C. Ezema ${ }^{2}$ \\ ${ }^{1}$ Department of Chemical, Metallurgical and Materials Engineering, Tshwane University of \\ Technology Pretoria, South Africa \\ ${ }^{2}$ Department of Metallurgical and Materials Engineering, University of Nigeria, Nsukka, Nigeria
}

(Received August 13, 2019; Revised October 8, 2019; Accepted November 29, 2019)

ABSTRACT. Lamination of fibre reinforced plastics (FRP) and catalytic curing of unsaturated polyester (UP) resin were the major focus of this study. The polyester resin was cured at ambient temperature with methyl ethyl ketone peroxide (MEKP) catalyst, cobalt octoate accelerator and phenol inhibitor. This was used to generate model equations that can predict the gel time of polyester resin when curing additives are added. The gelation was obtained by stirring $20 \mathrm{~g}$ of catalysed UP resin weighed into a plastic container until the viscosity suddenly increased. Gel times obtained were subjected to regression analysis and analysis of variance (ANOVA) so as to obtain the best predictive model. The ANOVA result showed that the gel time (Ti) in terms of inhibitor concentration, $\mathrm{Ti}=2820 \mathrm{i}-6$ was the best predictive equation of the gel time with a degree of accuracy of $98.89 \%$; where $\mathrm{i}$ is the inhibitor concentration. In the model, catalyst and accelerator are at constant concentrations of $1 \%$ and $0.5 \%$, respectively. The model was validated by laminating pilot components using hand lay-up technique. Thereafter, a laminating template was developed that would aid in reducing material wastes and lengthy down time during FRP lamination. This will be useful in increasing productivity and profitability in FRP small scale industry.

KEY WORDS: Polyester resin, Regression analysis, MEKP, Fibre reinforced plastics, Gel time, Phenol inhibitor, Cobalt octoate

\section{INTRODUCTION}

Unsaturated polyester (UP) resin is a type of polymer referred to as thermoset that transforms from liquid to solid state when subjected to the right condition of curing [1]. This curing condition can either be by adding heat or curing additives. Hence, as a thermoset, the curing reaction is irreversible. Most of the polyester resins are viscous and pale coloured liquids. However, styrene monomer is usually added to it to reduce its viscosity, improve its handle ability and facilitate its curability by cross-linking its molecular chains [2]. Figure 1 shows a typical polyester resin comprising the ester groups $(\mathrm{CO}-\mathrm{O}-\mathrm{C})$ and the reactive sites $\left(\mathrm{C}^{*}=\mathrm{C}^{*}\right)$ within the molecular chain. The styrene monomer gets attached to the reactive $\mathrm{C}^{*}$ site.

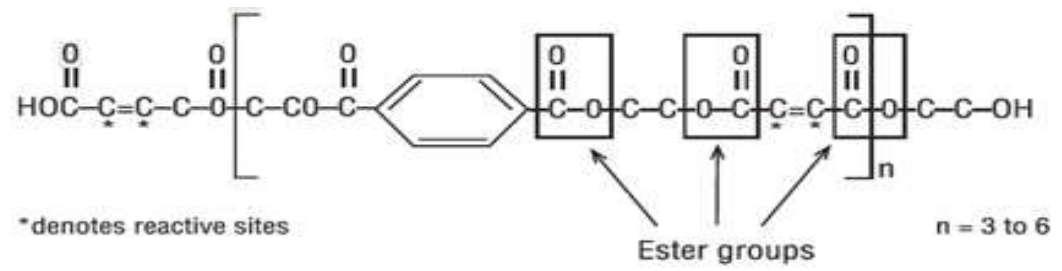

Figure 1. Structure of polyester resin [1].

${ }^{*}$ Corresponding author. E-mail: omega.ujah@gmail.com

This work is licensed under the Creative Commons Attribution 4.0 International License 
Polyester resin has high thermal stability and high weather resistance which made it a popular matrix for fabricating fibre reinforced plastic (FRP) products, insulation coatings and pultrusion components [2]. More so, its popularity is because of its low cost, its mechanical and chemical stability and its flexibility to many fabrication techniques [3]. FRP is a composite material comprising plastics (resin) and fiber glass whereby the resin is the matrix and the fiber glass is the reinforcement [4]. In such a fibre composite, the matrix binds the fibres so that all the stresses are transferred to the fibres.

Furthermore, polymerization of UP resin can be described as free radical chain growth cross linkage of styrene monomer and polyester double bond originating from unsaturated dicarboxylic acid. This is usually initiated by peroxides (catalyst) and activated by metallic compounds or tertiary amines in ambient temperature; or by the addition of heat [5-7]. Therefore, curing of the resin at ambient temperature needs a catalyst like methyl ethyl ketone peroxide (MEKP) which initiates polymerization, an accelerator like cobalt salt which promotes the reactivity of the catalyst and an inhibitor like quniones or phenols which homogenizes the curing kinetics [2]. By the addition of $2 \%$ MEKP and $0.02 \%$ cobalt octoate, Nasr and Azim [8] experienced substantial decrease in curing time. Hence, the addition of MEKP catalyst during polymerization of polyester resin is very important in inducing its curing kinetics just as the activity of Iron II in the body induces a plethora of biological catalysis [9].

Nonetheless, the period at which the viscosity of the polyester resin suddenly increases and reduces its flow, is termed the gel time of the resin. This is marked by a spontaneous decrease in the slurry of the resin system, which is the first stage of gelation. Therefore, lamination of a component with polyester must be completed before gelation sets in. This is because gelation is an irreversible transformation from controllable liquid state to an uncontrollable non-slurry gel. Hence, the accurate prediction of resin gelation is imperative in FRP lamination because it minimizes waste and increases productivity. Incidentally, gelation can be controlled by altering the amount of catalysts, accelerators and inhibitors incorporated into the resins during lamination [10]. Moreover, a good choice of these additives and the proportions at which they are added, according to Rodriguez [11], eliminate delay in gel time, lengthy down time and short exothermic reactions.

It is noteworthy to mention that the fundamental aim of a manufacturer is to maximize profit. One of the ways of achieving this is by overcoming operational challenges accruing from material wastes [12]. However, the major source of material waste during lamination is gelation before completion of the work. So, it is very necessary to have an accurate prediction of the gel time of the laminating resin in order to forestall this material waste. This forms the basis of this research. Moreover, production costs increase when material wastes increase and this diminishes profit. And one of the ways of eliminating material waste in fibre lamination is having a good knowledge and control of the curing kinetics of the resin. Hence, the production of FRP requires an in-depth knowledge of the curing times of the resin and its additives so as to eliminate losses caused by too fast curing, too slow curing or no curing at all. The approximate amount of resin curing additives was reported by Zhang [13], where the concentration of catalyst was between 1 to $3 \%$, accelerator was between 0.1 to $0.5 \%$, while inhibitor was between $0.05 \%$ to $0.3 \%$. Accordingly, [14] discovered that laminating with polyester resin at ambient temperature without a catalyst results to uncured moulding. However, Woods [15] itemized the curing rates of catalysed resins to comprise of $1 \%$ of catalyst for a slow cure, $2 \%$ for a normal cure, $3 \%$ for a fast cure, and 4\% (and above) result to cure failure. More so, Zhifeng et al. [16] observed that $3 \%$ of zirconium-containing mesoporous molecular sieve $\mathrm{SO} 4^{2-}$ /Zr-MCM-41 catalyst was the optimum weight percentage for producing tributyl citrate (TBC). It was stated also that too fast curing should be avoided because it shoots up the exothermic temperature which in turn induces cracks and fractures to the laminate [14]. A study by Yang, and Suspene [17] on inhibitor disclosed that it slows down curing reaction of the resin so as to have homogenous curing; and produces defect-free products. Secondly, it gives an induction 
period before the resin is cured and finally, adds storage life to resins. In the same vein, Woods [15] disclosed that inhibitor ensures that the peak exothermic temperature remains low so that fractures and cracks occasioned by very high thermal gradient are avoided. Yang and Suspene [17]worked on predicting the effect of MEKP and cobalt salt on the gel time of unsaturated polyester resin but did not incorporate inhibitor into the work. So, a model correlating curing temperature, initiator concentration, and acceleration concentration without inhibitor was developed. Hence, the contribution of inhibitor to the curing kinetics was not considered, which could affect the final product of FRP. Ramis and Salla [18] derived a mathematical relation for curing kinetics of polyester resins with varying levels of inhibitor in an unaccelerated polyester resin initiated by benzoyl peroxide. Here there was no accelerator. The absence of accelerator affected the response of the catalyst in initiating the polymerization and so, delayed the gelation period. Batch and Macosko [19] developed an expression for curing kinetics of UP resin with varying concentrations of diphenylpicrylhydrazyl inhibitor and azobisisobutyronitrile initiator; here there was no accelerator too. Hence, the curing reaction was not as precisely predictive as it would be in the presence of accelerator. Wayne et al. [20] worked on the kinetics of free radical initiation of polyester resins gel time by measuring the gel time and pseudo-adiabatic exotherm behaviour of resins initiated by varying amounts of two types of peroxide initiators, a cobalt accelerator and a free radical inhibitor, here two different catalysts were used, and this model may have compromised cost.

Therefore, it has been evident in the reviewed works and even in the literature that no author has reported a model that predicted the gel time of polyester resin catalysed by MEKP, accelerated by cobalt octoate and inhibited by phenols inhibitor despite the cost effectiveness and excellent properties of these additives, as Korhonen et al. and Laza et al. [21, 22] equally concurred. Hence, this study was aimed at generating a mathematical model that predicts the gel time of polyester resin cured with MEKP, cobalt octoate and phenol at ambient temperature using empirical and regression analyses; and validating the model with the lamination of some pilot components.

\section{EXPERIMENTAL}

UP resin (45\% in styrene) (99.9\% purity) and E-fibre glass $\left(450 \mathrm{~g} / \mathrm{m}^{2}\right)$ supplied by Dalian Bona Biological Technology Company, China, were used in this work. MEKP catalyst $(99.5 \%$ purity), cobalt octoate accelerator ( $99.9 \%$ purity) and phenol inhibitor ( $99.5 \%$ purity) were supplied by Anhui Eapearl Chemical Company Ltd, China. When experiment is designed and analyzed with statistical tools, useful information is usually translated into sound knowledge [23]. Accordingly, Ujah et al. [24] opined that a good experimental design improves consistency of performance and removes variation and noise. The improved performance of unsaturated polyester resin is achieved by the presence of more stearic hindrances introduced into the polymer backbone which increases its corrosion resistance and fewer beta-hydrogen which improves its weatherability. Nonetheless, the improved properties also affect the curing mechanism of the resin [23]. Therefore, there is the need for a thorough investigation on the curing kinetics of the resins. For this reason, the gel time experiment was divided into three stages, which included catalyst variation, accelerator variation and inhibitor variation. In catalyst variation, the aim was to investigate the effect of increasing the concentration of catalyst on gel time of the resin while the concentration of accelerator and inhibitor were kept constant. In accelerator variation, it was designed to investigate the effect of accelerator on the gel time of polyester resin, by keeping the concentration of catalyst and inhibitor constant. The inhibitor variation was geared towards discovering the effect of inhibitor on the gel time of resin while concentration of the catalyst and accelerator was kept constant. The next stage of the experiment involved analysing the three effects of the additives on the UP resin with regression analysis. The final stage of the study was validating the best model equation by laminating various pilot 
components using hand lay-up technique. A laminating guide template for FRP was finally arranged to serve as a handy tool in FRP lamination.

In resin curing experiment, $20 \mathrm{~g}$ of polyester resin was weighed into a plastic container as shown in Figure 2. Then $2 \mathrm{wt} \%$ of accelerator and $0.002 \mathrm{wt} \%$ of inhibitor were added. This was followed by adding $0.3 \mathrm{wt} \%$ of catalyst to the mixture and stirring until it gelled. The gel time was recorded as the interval between the addition of the catalyst and the point when the viscosity of the resin thickened. In other words, gel time can be described as the time when the liquid mass starts turning into a gel-like substance [25]. This was always marked by a sudden increase in temperature which can be felt on the container as resin curing is an exothermic reaction [1]. The same procedure was repeated for 19 times, increasing the concentration of catalyst from $0.3 \mathrm{wt} \%$ to $3.15 \mathrm{wt} \%$ and recording the gel times. In the second stage, 20 reactions were carried out. But now, catalyst and inhibitor were kept at constant values of $1 \%$ and $0.01 \%$, respectively, while the quantity of accelerator was increased from $0.01 \%$ to $0.575 \%$. However, catalyst was always the last ingredient added because curing reaction begins as soon as catalyst was added unto the resin. Then the mixture was stirred until it gelled (all the tests were carried out at ambient temperature of $25^{\circ} \mathrm{C}$ and humidity of $60 \%$ ). For inhibitor experiment, $0.5 \%$ of accelerator and $1 \%$ of catalyst were kept constant while the concentration of inhibitor was varied from $0.005 \%$ to $0.024 \%$.

To validate the gel time model equation, some pilot components were laminated using hand lay-up process with UP resin and E-fiber glass reinforcement. This hand lay-up method was adopted following [1] who disclosed that the method is the simplest technique, cheapest to undertake, accommodates higher fibre contents, absorbs longer fibres and has wide choice of material. Furthermore, it was observed in [14] that hand lay-up equipment does not require special technology before handling, the technique has no size and shape restriction, and it can accommodate other reinforcing phases like wood, metals and foam. Firstly, a Honda fender was laminated. The Honda Fender had three plies. A gel time of 40 minutes (with the corresponding mixture) was adopted for the work and this was chosen such that the fibre wetting out was completed before gelation. Material requirement was calculated using method developed by Gurit [1]. A mould was constructed with mild steel of surface area of $0.426 \mathrm{~m}^{2}$. As the laminate was designed to carry 3 plies of $450 \mathrm{~g} / \mathrm{m}^{2}$ fiber glass, the material requirement as earlier said was calculated using method given in [1] as follows:

$R_{W}=2_{n}\left(W_{f} A\right)$

where $R_{w}$ is resin weight $(\mathrm{g}), \mathrm{n}$ is number of plies of the laminate, $\mathrm{W}_{\mathrm{f}}$ is fibre weight of each ply $\left(\mathrm{g} / \mathrm{m}^{2}\right)$, and $\mathrm{A}$ is surface area of the mould.

With equation 1, weight of fibre mat $=450 \mathrm{~g} / \mathrm{m}^{2} \times 0.426 \mathrm{~m}^{2}=191.7 \mathrm{~g}$ of mat per ply; this gave $383.4 \mathrm{~g}$ of resin per ply. With equation $5, \mathrm{~T}_{\mathrm{i}}=2820 \mathrm{i}-6$ which was the best gel time equation, the mixing ratio that gelled in $40 \mathrm{~min}$ was got as $3.83 \mathrm{~g}$ MEKP catalyst, $1.92 \mathrm{~g}$ cobalt accelerator, and $0.06 \mathrm{~g}$ of phenol inhibitor per ply. Therefore, multiplying all by 3 , the resin, accelerator and inhibitor were weighed out and mixed gently but thoroughly to ensure that no air was trapped into the mixture while the additives were homogeneously dispersed. During mould preparation, the mould was washed and dried. It was polished with wax and allowed to dry. Polyvinyl acetate (PVA) was finally applied for easy demoulding of the work after curing [4]. Then fibre mat was cut into the shape of the mould and laid unto the prepared mould. This mould preparation was done before the resin additives were weighed into the resin. The mixed resin was poured on the fibre plies that were laid in the mould and with roller and brush, the fibre plies were impregnated with the resin. Lamination was completed before the gel time. The composite was left for 24 hours before demoulding. The next component laminated was Golf bumper. The mould was built as usual with mild steel having the surface areas of the following. The base was $0.199 \mathrm{~m}^{2}$, the inclined surface was $0.124 \mathrm{~m}^{2}$ and the two arms was $0.082 \mathrm{~m}^{2}$ each. The fibre mat weight was calculated as follows: base $=450 \mathrm{~g} / \mathrm{m}^{2} \times 0.199 \mathrm{~m}^{2}=89.55 \mathrm{~g}$ per ply; 
inclined surface $=55.8 \mathrm{~g}$ per ply, arm $=36.9 \mathrm{~g}$ per ply. Resin required was 2 times the weight of the fibre mats' as seen in the first lamination. The lamination was structured in four sections due to the shape of the component. For the base, the lamination was scheduled for $20 \mathrm{~min}$, the inclined surface was scheduled for another $20 \mathrm{~min}$ and the two arms were scheduled for $10 \mathrm{~min}$ each; and using equation 5, the curing additives were weighed out accordingly. For a Honda bonnet, the surface area was $1.229 \mathrm{~m}^{2}$ for the main body and $0.699 \mathrm{~m}^{2}$ for each of the stiffening membranes. The mould was built with mild steel. The stiffening membranes were wetted out on a steel platform and then bonded together with the main body with fast curing resin and clamp after they had cured separately. For a Honda booth, the lamination was sectioned into three parts as the shape does not permit lamination of the whole part simultaneously. The flat surface of area $0.383 \mathrm{~m}^{2}$ was first done and allowed to gel followed by the inclined surface of area 0.412 $\mathrm{m}^{2}$. The stiffening membrane of surface area $0.494 \mathrm{~m}^{2}$ was then done and bonded unto the main body with the same process described above in the lamination of bonnet. The material requirements were calculated using the methods described above too. A mirror holder has surface area of $0.027 \mathrm{~m}^{2}$ and was laminated after calculating the material requirements, cutting the fibre mat into shape and mixing the curing additive that would gel in $20 \mathrm{~min}$. A motorcycle engine side cover has surface area of $0.066 \mathrm{~m}^{2}$. Using the same method described above, the component was laminated with 3 plies of fibre mat.

\section{RESULTS AND DISCUSSION}

Figure 2 displays picture of some UP resin cured at ambient temperature, with the help of MEKP catalyst, cobalt accelerator and phenol inhibitor. Curing of polyester resin begun with gelling, which can be described as changing of the resin from liquid to semi solid or paste form. However, lamination of FRP should be completed before gelling commences [1]. This is because when gelation sets in, the resin cannot be controlled any more. Its viscosity increases, thereby reducing its flexibility and control [4]. So, a laminator should always adopt curing time that is long enough to accommodate full impregnation of the fibre and short enough to avoid lengthy down time.

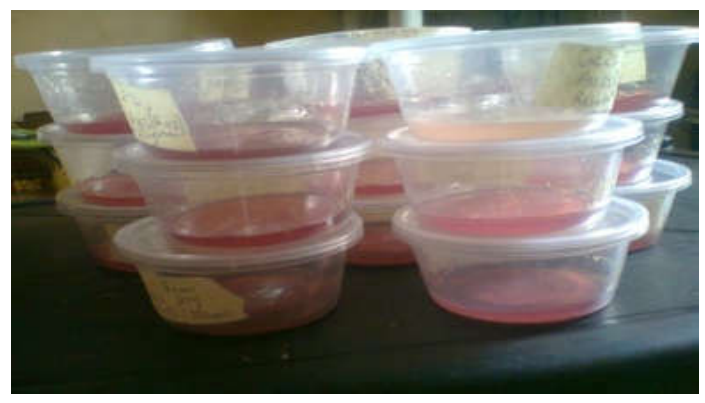

Figure 2. Pictures of cures polyester resin.

Figure 3 displays plots of predictor variables versus response variable. Here, it was observed that an increase in concentration of catalyst led to a decrease in gel times (Figure 3a). A regression equation generated by Minitab from the plot of Figure 3a was as follows:

$T_{C}=28.7-9.7 c$ 
where $T_{c}$ is gel time in terms of catalyst, $\mathrm{c}$ is the weight percentage concentration of catalyst. In Figure $3 \mathrm{~b}$, increase in the concentration of accelerator led to decrease in gel time too. The regression equation generated was as follows:

$T_{a}=50.7-79.5 a$

where $T_{a}$ is the gel time in terms of accelerator, $a$ is the weight percentage of accelerator. Figure $3 \mathrm{c}$ shows that increase in inhibitor led to increase in the gel times. A regression equation from the plot was as follows:

$T_{i}=-5.8+2820.1 i$

Or in an abridged form,

$T_{i}=2820 i-6$

where $\mathrm{Ti}$ is the gel time of resin in terms of inhibitor, $\mathrm{i}$ is the percentage weight of inhibitor.

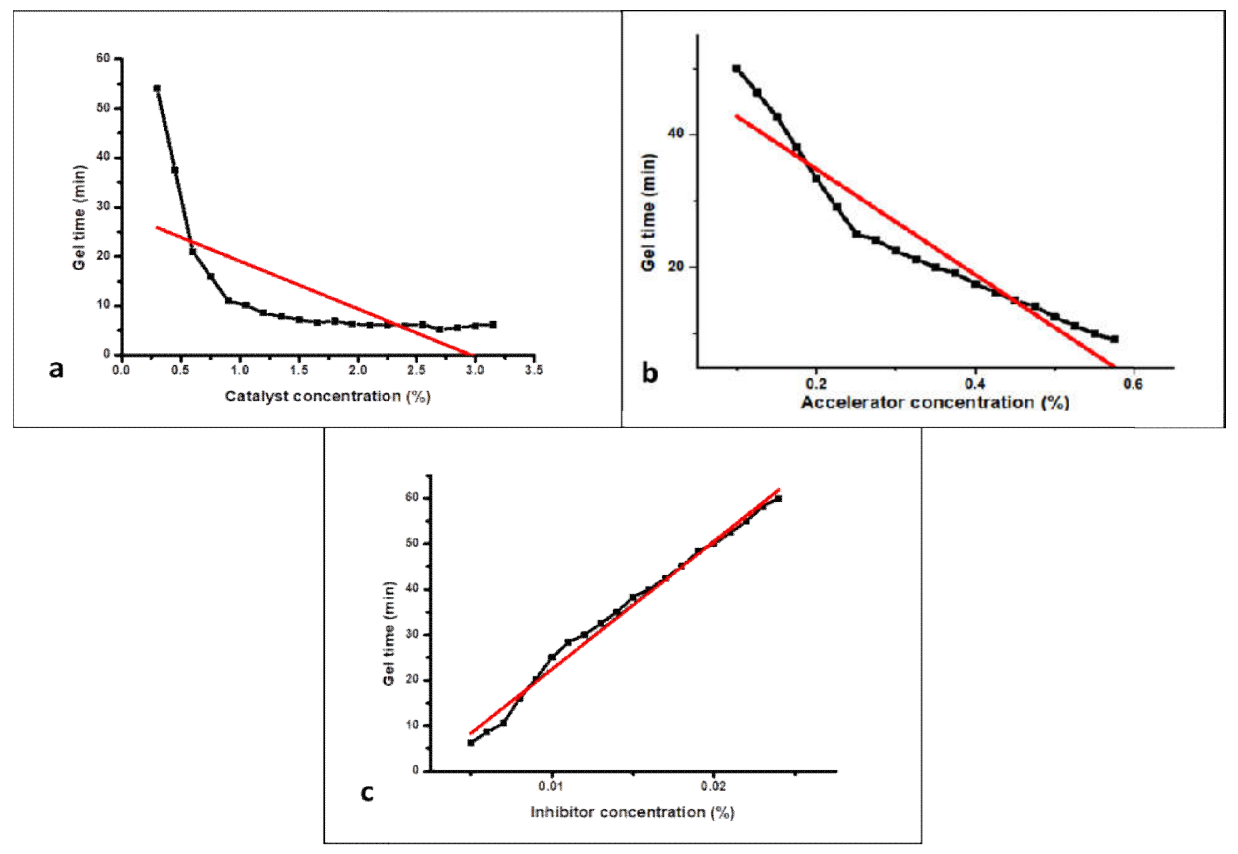

Figure 3. Gel time Profiles of: (a) catalyst, (b) accelerator and (c) inhibitor variations.

Table 1 displays the results of curing time of polyester resin with the addition of catalyst, accelerator and inhibitor. Gel time 1 was the result got from varying the concentration of catalyst while accelerator and inhibitor were held constant at $2 \%$ and $0.002 \%$, respectively. Gel time 2 was the result got from varying accelerator while keeping catalyst and inhibitor at $1 \%$ and $0.01 \%$, respectively. Gel time 3 was the result got when inhibitor was varied and catalyst and accelerator were kept at $1 \%$ and $0.5 \%$, respectively.

To verify the best model for predicting the gel time from the three regression equations, Analysis of variance (ANOVA) was employed and the result was as given in Table 2. 
Table 1. Result of gel times of polyester resin.

\begin{tabular}{|c|c|c|c|c|c|c|}
\hline $\begin{array}{c}\text { Experiment } \\
\text { no }\end{array}$ & $\begin{array}{c}\text { Catalyst } \\
(\%)\end{array}$ & $\begin{array}{c}\text { Gel time 1 } \\
(\mathrm{min})\end{array}$ & $\begin{array}{c}\text { Accelerator } \\
(\%)\end{array}$ & $\begin{array}{c}\text { Gel time 2 } \\
(\mathrm{min})\end{array}$ & $\begin{array}{c}\text { Inhibitor } \\
(\%)\end{array}$ & $\begin{array}{c}\text { Gel time 3 } \\
(\mathrm{min})\end{array}$ \\
\hline 1 & 0.30 & 54.00 & 0.10 & 50.00 & 0.005 & 6.20 \\
\hline 2 & 0.45 & 37.50 & 0.125 & 46.35 & 0.006 & 8.60 \\
\hline 3 & 0.60 & 21.00 & 0.15 & 42.70 & 0.007 & 10.50 \\
\hline 4 & 0.75 & 16.00 & 0.175 & 38.02 & 0.008 & 16.00 \\
\hline 5 & 0.90 & 11.00 & 0.20 & 33.34 & 0.009 & 20.30 \\
\hline 6 & 1.05 & 10.15 & 0.225 & 29.17 & 0.010 & 25.00 \\
\hline 7 & 1.20 & 8.50 & 0.25 & 25.00 & 0.011 & 28.30 \\
\hline 8 & 1.35 & 7.80 & 0.275 & 24.15 & 0.012 & 30.00 \\
\hline 9 & 1.50 & 7.23 & 0.30 & 22.50 & 0.013 & 32.50 \\
\hline 10 & 1.65 & 6.59 & 0.325 & 21.25 & 0.014 & 35.00 \\
\hline 11 & 1.80 & 6.90 & 0.35 & 20.00 & 0.015 & 38.30 \\
\hline 12 & 1.95 & 6.30 & 0.375 & 19.15 & 0.016 & 40.00 \\
\hline 13 & 2.10 & 6.10 & 0.40 & 17.50 & 0.017 & 42.50 \\
\hline 14 & 2.25 & 6.10 & 0.425 & 16.25 & 0.018 & 45.00 \\
\hline 15 & 2.40 & 6.00 & 0.45 & 15.00 & 0.019 & 48.30 \\
\hline 16 & 2.55 & 6.20 & 0.475 & 14.15 & 0.020 & 50.00 \\
\hline 17 & 2.70 & 5.20 & 0.50 & 12.50 & 0.021 & 52.50 \\
\hline 18 & 2.85 & 5.58 & 0.525 & 11.25 & 0.022 & 55.00 \\
\hline 19 & 3.00 & 6.00 & 0.55 & 10.00 & 0.023 & 58.30 \\
\hline 20 & 3.15 & 6.20 & 0.575 & 9.12 & 0.024 & 60.00 \\
\hline
\end{tabular}

\section{Percentage error values}

The principal aim of generating a regression line is to create a line from a given data that reduces sum of squared errors (SSE) to the smallest possible value. This means that line with least error value automatically becomes the best prediction line. It was observed from Table 2 that $\mathrm{T}_{\mathrm{i}}$ has the lowest error level and hence the best model.

Table 2. Analysis of variance for the regression equations.

\begin{tabular}{|l|c|c|c|}
\hline & $\mathrm{T}_{\mathrm{c}}$ & $\mathrm{T}_{\mathrm{a}}$ & $\mathrm{T}_{\mathrm{i}}$ \\
\hline Equation & {$\left[\mathrm{T}_{\mathrm{c}}=28.7-9.7 \mathrm{c}\right]$} & {$\left[\mathrm{T}_{\mathrm{a}}=50.7-79.5 \mathrm{a}\right]$} & {$\left[\mathrm{T}_{\mathrm{i}}=-5.8+2820.1 \mathrm{i}\right]$} \\
\hline Error & 9.27 & 3.75 & 1.81 \\
\hline $\mathrm{R}$ - sq. & $47.59 \%$ & $91.21 \%$ & $98.89 \%$ \\
\hline $\mathrm{R}$ - sq. (adj) & $44.68 \%$ & $90.72 \%$ & $98.83 \%$ \\
\hline $\mathrm{F}$ - value & 16.35 & 186.78 & 1609.18 \\
\hline $\mathrm{P}$ - value & 0.001 & 0.000 & 0.000 \\
\hline
\end{tabular}

\section{$R$-Squared values $\left(R^{2}\right)$}

This is otherwise called coefficient of determination (COD) and is the quotient of sum of square (SSR) of regression to total sum of square (SST), mathematically expressed as follows:

$$
R^{2}=\frac{S S R}{S S T}
$$

This tries to explain the percentage of the total sum of squares which can be explained by using the regression equation in question. For $\mathrm{T}_{c}$, the $\mathrm{R}^{2}$ is $47.59 \%$. This means that $47.59 \%$ of the total sum of squares can be explained by using the estimated regression equation of $\mathrm{T}_{\mathrm{c}}$ to predict the gel time of the resin. In other words, it can be said that the use of $\mathrm{T}_{\mathrm{c}}$ equation can predict the 
outcome of gel time of UP resin by $47.59 \%$ with $95 \%$ confidence level [24]. More so, the $\mathrm{R}^{2}$ for $\mathrm{T}_{\mathrm{a}}$ is $91.21 \%$ and that of $\mathrm{T}_{\mathrm{i}}$ is $98.89 \%$. Therefore, in terms of $\mathrm{R}^{2}, \mathrm{~T}_{\mathrm{i}}$ is still the best as it has the highest value.

P-values

$\mathrm{P}$-value is the probability of getting an F-value that is larger than that in question given that there is no effect of other variables being considered. This tries to establish whether or not the response is statistically significant. For $95 \%$ confidence level, the P-value must be less than 0.05 for the outcome to be significant. Hence, from the table, it was observed that all the P-values are approximately zero. So, the three correlations are statistically significant. However, F-value of $\mathrm{T}_{\mathrm{i}}$ is far much higher than the other two. So, it is more significant. Therefore, it can be said from the ANOVA results that $\left[\mathrm{T}_{\mathrm{i}}=2820 \mathrm{i}-6\right]$ is the best correlation equation to predict the gel time.

Figure 4 shows the pictures of laminated components. Figure 4 a shows the laminated fender while $4 \mathrm{a}^{\prime}$ shows the computer aided design (CAD) of the fender. During the lamination, the stress area was the curved edges which needed to be stamped very well in order to get the shape well carved out. The work was completed within the estimated time of $40 \mathrm{~min}$. For demoulding operation, hammer and punches were used although the polishing and PVA applied prior to moulding aided in easy demoulding of the laminate [14]. Figure $4 \mathrm{~b}$ shows the laminate of Golf bumper while $4 \mathrm{~b}$ ' is the CAD. Due to the nature of the component, its lamination was sectioned into 4 parts in such a way that as the first section gelled, the mould was turned around so that resin would not drip out while the next part was laminated. This process was adopted in laminating shapes that are not wholly flat in order to avoid resin drip which causes resin pocket, pimple and other defects in FRP laminates [26]. The area of concentration in this laminate was the joints where the section parts met. It should be noted that FRP joints must be carefully handled since they entail discontinuities in the configuration of the structure and all failures are concentrated there in [27]. Figure $4 c$ shows laminated Honda bonnet while $4 c$ is the CAD of the component. This component was laminated with three plies for the main body and two plies for the inner lining. The function of inner lining was to add strength to the edge which experiences tensile stress from frequent opening and closing and ensure optimum performance in service [28]. The two parts were separately moulded and joined with fast curing resin after they had cured separately. The fastest curing resin used was 10 min since too fast curing will cause wrinkle or cracks in the final product [15]. Figure $4 \mathrm{~d}$ shows the booth while $4 \mathrm{~d}^{\prime}$ is the CAD of the booth. This component was laminated in three parts; the flat surface, the inclined surface and the stiffening membrane to ensure that resin drip was avoided. The stress area was the inclined surface which has a concave protrusion. So it was given 50 min which was enough for fibre impregnation before the resin gelled. The protrusion needed some concentration with thorough stamping of the resin into the fibre. Another stressful part was joining of the two parts with the stiffening membrane. This was achieved with fast curing resin and a G-clamp. For mirror holder and engine side cover, mould preparation was a key factor because small component always got destroyed during demoulding. So in order to avert this problem, mould was properly prepared by applying generous wax and PVA [26]. 

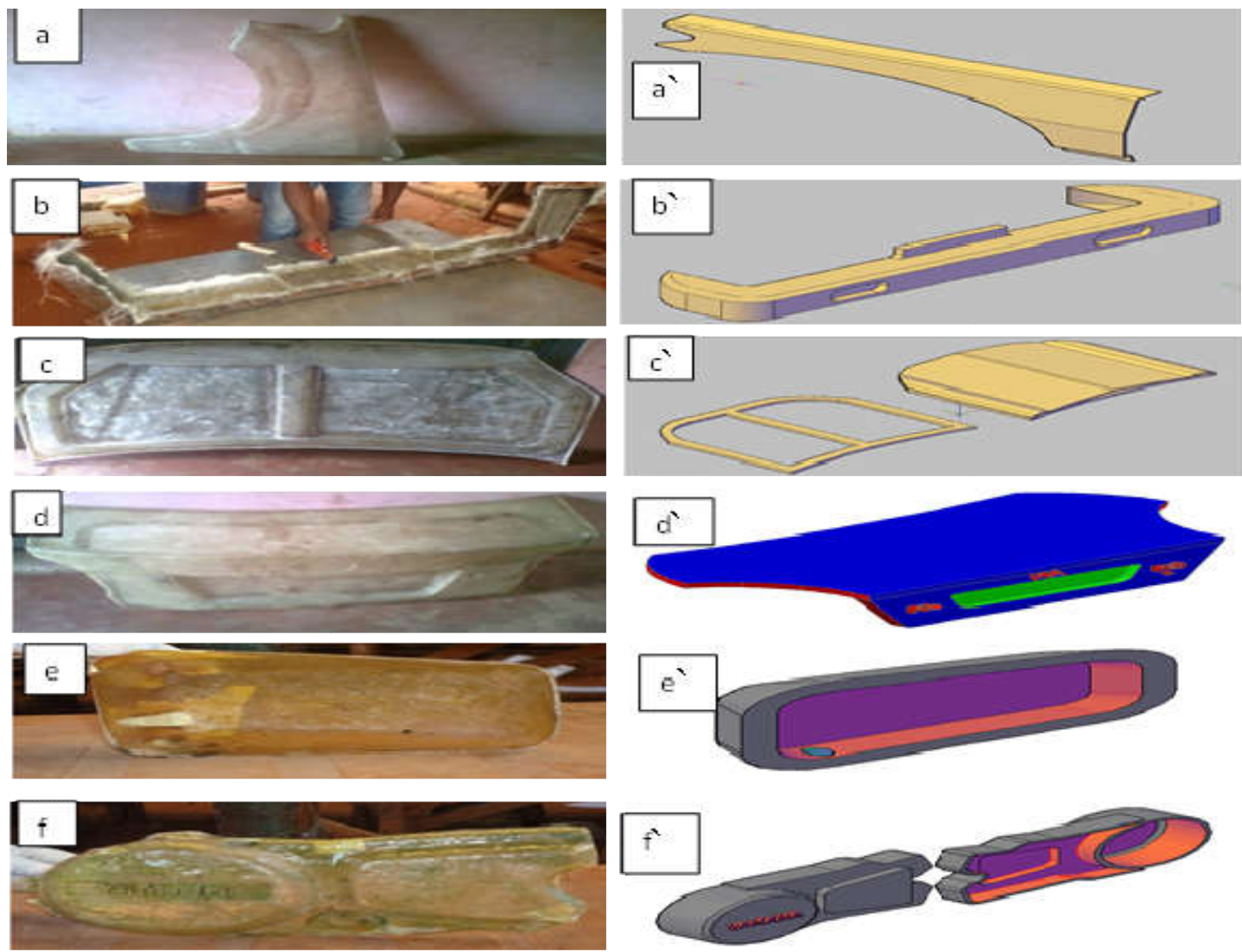

Figure 4. Pictures of laminated pilot components of: (a) Honda fender, (b) Golf bumper, (c) Honda bonnet, (d) Honda Booth, (e) Side mirror holder and (f) Motorcycle engine side cover.

Table 3 shows a lamination guide template which will save laminators the stress of rigorous calculations or trial and error manipulation of curing times. This was developed with the use of the best predictive model (equation 5).

The choice of inhibitor concentration depends on the enormity of the work or the expertise of the laminator. If the work is light, inhibitor for shorter time is chosen but if the work is heavy, inhibitor for longer time will be chosen. Likewise a skilful worker uses shorter time than an inexperienced one. So Table 3 can be used by every laminator. Once the area of the work is obtained, the fibre and resin quantities are calculated using method by [1] and the resin mixture selected appropriately from the table. 
Table 3. FRP lamination template.

\begin{tabular}{|c|c|c|c|c|c|c|c|c|}
\hline $\begin{array}{c}\text { Resin } \\
{\left[\begin{array}{c}\mathrm{UP}] \\
(\mathrm{g})\end{array}\right.}\end{array}$ & $\begin{array}{c}\text { Catalyst } \\
{[\mathrm{MEKP}]} \\
(\mathrm{g})\end{array}$ & $\begin{array}{c}\text { Accelerator } \\
{[\text { Cobalt }]} \\
(\mathrm{g})\end{array}$ & $\begin{array}{c}\text { Inhibitor } \\
{[\text { Phenol }]} \\
(\mathrm{g}) \\
{[10 \mathrm{~min}]}\end{array}$ & $\begin{array}{c}\text { Inhibitor } \\
{[\text { Phenol }]} \\
(\mathrm{g}) \\
{[20 \mathrm{~min}]}\end{array}$ & $\begin{array}{c}\text { Inhibitor } \\
{\left[\begin{array}{c}\text { Phenol }] \\
(\mathrm{g}) \\
{[30 \mathrm{~min}]}\end{array}\right.}\end{array}$ & $\begin{array}{c}\text { Inhibitor } \\
{[\text { Phenol }]} \\
(\mathrm{g}) \\
{[40 \mathrm{~min}]}\end{array}$ & $\begin{array}{c}\text { Inhibitor } \\
{[\text { Phenol }]} \\
(\mathrm{g}) \\
{[50 \mathrm{~min}]}\end{array}$ & $\begin{array}{c}\text { Inhibitor } \\
{[\text { Phenol }]} \\
(\mathrm{g}) \\
{[60 \mathrm{~min}]}\end{array}$ \\
\hline 50 & 0.50 & 0.25 & 0.003 & 0.005 & 0.006 & 0.008 & 0.010 & 0.012 \\
\hline 100 & 1.00 & 0.50 & 0.006 & 0.009 & 0.013 & 0.016 & 0.020 & 0.023 \\
\hline 150 & 1.50 & 0.75 & 0.009 & 0.014 & 0.019 & 0.024 & 0.030 & 0.035 \\
\hline 200 & 2.00 & 1.00 & 0.011 & 0.018 & 0.027 & 0.033 & 0.040 & 0.047 \\
\hline 250 & 2.50 & 1.25 & 0.014 & 0.023 & 0.032 & 0.041 & 0.050 & 0.059 \\
\hline 300 & 3.00 & 1.50 & 0.017 & 0.028 & 0.038 & 0.049 & 0.060 & 0.070 \\
\hline 350 & 3.50 & 1.75 & 0.020 & 0.032 & 0.045 & 0.057 & 0.070 & 0.082 \\
\hline 400 & 4.00 & 2.00 & 0.023 & 0.037 & 0.051 & 0.065 & 0.079 & 0.094 \\
\hline 450 & 4.50 & 2.25 & 0.024 & 0.041 & 0.058 & 0.073 & 0.089 & 0.105 \\
\hline 500 & 5.00 & 2.50 & 0.028 & 0.046 & 0.064 & 0.082 & 0.099 & 0.117 \\
\hline 550 & 5.50 & 2.75 & 0.031 & 0.051 & 0.070 & 0.090 & 0.109 & 0.129 \\
\hline 600 & 6.00 & 3.00 & 0.034 & 0.055 & 0.077 & 0.098 & 0.119 & 0.140 \\
\hline 650 & 6.50 & 3.25 & 0.037 & 0.060 & 0.083 & 0.106 & 0.129 & 0.152 \\
\hline 700 & 7.00 & 3.50 & 0.040 & 0.065 & 0.090 & 0.114 & 0.139 & 0.164 \\
\hline 750 & 7.50 & 3.75 & 0.043 & 0.069 & 0.096 & 0.122 & 0.149 & 0.176 \\
\hline 800 & 8.00 & 4.00 & 0.045 & 0.074 & 0.102 & 0.130 & 0.159 & 0.187 \\
\hline 850 & 8.50 & 4.25 & 0.048 & 0.078 & 0.109 & 0.139 & 0.169 & 0.199 \\
\hline 900 & 9.00 & 4.50 & 0.051 & 0.083 & 0.115 & 0.147 & 0.179 & 0.211 \\
\hline 950 & 9.50 & 4.75 & 0.054 & 0.088 & 0.122 & 0.155 & 0.189 & 0.222 \\
\hline 1000 & 10.00 & 5.00 & 0.057 & 0.092 & 0.128 & 0.163 & 0.199 & 0.234 \\
\hline
\end{tabular}

\section{CONCLUSION}

Experimental and statistical studies for predicting the gel time of UP resin with its curing additives have been conducted. It can be concluded that adequate information and knowledge on gel times of resin and its curing additives contribute immensely in saving processing time and preventing material wastes in fibre reinforced plastics lamination. From the study, the best model to predict the gel times of polyester resin at ambient temperature was $T_{i}=2820_{i}-6$; where $T_{i}$ was the gel time in terms of phenol inhibitor in minutes, $i$ was the percentage weight of inhibitor while MEKP catalyst and cobalt accelerator concentrations were $1 \mathrm{wt} \%$ and $0.5 \mathrm{wt} \%$, respectively. It was found that increment of the percentage of catalyst with the intention of achieving fast cure should be discouraged in FRP lamination because the reaction does not follow a linear and predictable trend. Furthermore, the lamination of the composites with the aim of validating the model equation was successfully achieved and therefore, the model equation was valid. Finally, the lamination template developed in this work will go a long way in helping to reduce lengthy down time, material wastes and production bottle neck of FRP.

\section{ACKNOWLEDGEMENT}

The authors would like to acknowledge Centre for Energy and Electric Power (CEEP), Tshwane University of Technology, Pretoria for providing financial aid in parts for this project. 


\section{REFERENCES}

1. Research. Guide to composites, September 2019. Available at: http://www.gurit.com.

2. Waigaonkar, S.; Babu, B.; Rajput, A. Curing Studies of Unsaturated Polyester Resin Used in FRP Products, Jaico: India; 2011; 123.

3. Ton-That, M.T.; Cole, K.; Jen, C.K.; Franca, D. Polyester cure monitoring by means of different techniques. Polym. Compos. 2000, 21, 605-618.

4. Research. A beginner's guide to Fibre reinforced plastics (FRPs), October 2019. Available at: https://www.craftechind.com/beginners-guide-fiber-reinforced-plastics-frps/.

5. Horie, K.; Hiura, H.; Sawada, M.; Mita, I. Kambe, H. Calorimetric investigation of polymerization reactions. III. Curing reaction of epoxides with amines. J. Polym. Sci. Part A-1 1970, 8, 1357-1372.

6. Yang, Y.; Lee, L.J. Polymerization of polyurethane-polyester interpenetrating polymer network (IPN). Macromolecules 1987, 20, 1490-1495.

7. Yang, Y.; L.J. Lee, L.J. Microstructure formation in the cure of unsaturated polyester resins. Polym. 1988, 29, 1793-1800.

8. Nasr, E.S.; A.A. Abdel-Azim, A.A. The effect of curing conditions on the physical and mechanical properties of styrenated polyester. Polym. Adv. Technol. 1992, 3, 407-411.

9. Zhai, Q.-Z. Kinetic spectrophotometric determination of iron based on catalytic oxidation of p-acetylarsenazo. Bull. Chem. Soc. Ethiop. 2009, 23, 445-450.

10. Kuppusamy, R.R.P.; Neogi, S. Influence of curing agents on gelation and exotherm behaviour of an unsaturated polyester resin. Bull. Mater. Sci. 2013, 36, 1217-1224.

11. Rodriguez, E.L. The effect of free radical initiators and fillers on the cure of unsaturated polyester resins. Polym. Eng. Sci. 1991, 31, 1022-1028.

12. Fadeyi, J.; Oguoma, O.; Ogbonnaya, E. Performance optimizing of a sanitary towel production plant using reliability model. Nig. J. Technol. 2013, 32, 101-108.

13. Zhang, S. Nanostructured thin films and coatings: mechanical properties. CRC Press: England; 2010; p 257.

14. Research. Hand Lay-up Process Advantages and Disadvantages, September 2019. Available at: http://www.unicomposite.com/news/hand-lay-up-process-advantages-and-disad.html

15. Wood, R. Automotive Engineering Plastics, Society of Automotive Engineers: England; 1991.

16. Zhifeng, Z.; Junming, X.; Jianchun, J.; Yanju, L.; Yuanbo, H. Synthesis of tributyl citrate using $\mathrm{SO}_{4}{ }^{2-} / \mathrm{Zr}-\mathrm{MCM}-41$ as catalyst. Bull. Chem. Soc. Ethiop. 2011, 25, 147-150.

17. Yang, Y.S.; Suspene, L. Curing of unsaturated polyester resins: Viscosity studies and simulations in pre-gel state. Polym. Eng. Sci. 1991, 31, 321-332.

18. Ramis, X.; Salla, J.M. Time-temperature transformation (TTT) cure diagram of an unsaturated polyester resin. J. Polym. Sci. Part B: Polym. Phys. 1997, 35, 371-388.

19. Batch, G.L.; Macosko, C.W. Kinetic model for crosslinking free radical polymerization including diffusion limitations. Appl. Polym. Sci. 1992, 44, 1711-1729.

20. Cook, W.D.; Lau, M.; Mehrabi, M.; Dean, K.; Zipper, M. Control of gel time and exotherm behaviour during cure of unsaturated polyester resins. Polym. Int. 2001, 50, 129-134.

21. Korhonen, M.; Starck, P.; Löfgren, B.; Mikkilä, P.; Hormi, O. Study of polyester-based coil coatings by using thermal analysis methods. Coat. Technol. 2003, 75(937), 67-73.

22. Laza, J.; Vilas, J.; Rodriguez, M.; Garay, M.; Mijangos, F.; Leon, L. Analysis of the crosslinking process of a phenolic resin by thermal scanning rheometry. Appl. Polym. Sci. 2002, 83, 57-65.

23. Bogner, B.R.; Breitigam, W.V.; Woodward, M.; Forsdyke, K.L. Thermoset resins for pultrusion, in Pultrusion for Engineers, Woodhead Publishing: Cambridge, England; 2000, 97-174. 
24. Ujah, C.O.; Popoola, A.P.; Popoola, O.M.; Aigbodion, V.S. Optimisation of spark plasma sintering parameters of Al-CNTs-Nb nano-composite using Taguchi Design of Experiment. Int. J. Adv. Manuf. Technol. 2019, 100, 1563-1573.

25. Hinrichs, R.J. Rheological Cure Transformation Diagrams for Evaluating Polymer Cure Dynamics, ACS Publications: USA; 1983.

26. McVeigh, J.; Anmarkrud, T.; Gulbrandsen, O.; Ravikumar, R.; Danielsson, P.; Gudmundsson, A. Training manual on the Construction of FRP Beach Landing Boat, FAO: Rome; 2010.

27. Banea, M.; da Silva, L.F. Adhesively bonded joints in composite materials: an overview, Proceedings of the Institution of Mechanical Engineers. Mater. Design Appl. 2009, 223, 118.

28. Bogner, B.; Sumbry, L. FRP linings in aboveground storage tanks. Arab. J. Sci. Eng. 1995, 20,361-361. 